Article

\title{
Usability of the EPC Tools for the Profitability Calculation of a Retrofitting in a Residential Building
}

\author{
Alex Gonzalez Caceres ${ }^{1,2, *(1)}$ and Muriel Diaz ${ }^{3}$ \\ 1 Department of Civil Engineering, Technical University of Denmark, Building 118, Room 243, \\ 2800 Kgs. Lyngby, Denmark \\ 2 Department of Civil Engineering and Energy Technology, OsloMet-Oslo Metropolitan University, \\ Postboks 4 St. Olav plass, 0130 Oslo, Norway \\ 3 Departamento de Diseño y Teoría de la Arquitectura, Universidad del Bío-Bío, Av. Collao 1202, \\ 4051381 Concepción, Chile; madiazc@ubiobio.cl \\ * Correspondence: aagc@byg.dtu.dk or alexgc@oslomet.no; Tel.: +47-4772-2563
}

Received: 14 July 2018; Accepted: 31 August 2018; Published: 4 September 2018

\begin{abstract}
After the oil crisis in the 70s energy regulation codes were implemented, but a great portion of existing dwellings have not been retrofitted to current requirements. To face this issue several actions were taken in the European Union (EU), among these, the implementation of Energy Performance Certificates (EPC), which include a Recommendation List of Measures (RLMs) to retrofit buildings. Some concerns exist about the lack of confidence on these recommendations. The main objective of this study is to analyze the usefulness of the EPC, answering if it is possible to deliver a realistic financial assessment about renovation strategies using these tools. The study is based on three indicators: Consumption, energy saving variations and profitability. The study is based on a renovation project case study, where simulations and Life Cycle Cost Assessment (LCCA) were performed, in order to identify the different results that EPC's and an energy efficiency assessment could lead to. The results show important differences in all the concepts evaluated.
\end{abstract}

Keywords: EPC; labeling; simulation; performance gap; EPBD

\section{Introduction}

The renovation project of a building needs to define, via a preliminary study, the most effective renovation measurements in terms of energy savings and indoor environment improvement considering that these measures will result in a significant cost to the building owners. Therefore, the recovery of the investment and the initial cost is one of the most important aspects considered by the owners before undertaking a renovation [1]. As stated on the Energy Performance Building Directive (EPBD) [2], an Energy Performance Certificate (EPC) is needed whenever a building is constructed, or in the case of existing buildings, before it is marketed for sale or rent. The certificate includes the overall energy performance of the building and reference values such as the minimum energy performance requirements, allowing the comparison with another building of the same type [3]. For existing buildings, additionally, the EPC is expected to include a list of cost-optimal or cost-effective measures to improve the energy performance of buildings, these recommendations may provide an estimate for the payback time or cost-benefits over its economic lifecycle. This element on the EPC, to provide energy recommendations for retrofitting building in mass, represents an attractive solution to improve the existing residential building stock, which is the main source of $\mathrm{CO}_{2}$ emissions in the building sector [4]. However, certain factors must be considered to affirm that EPC recommendations are effective and therefore it is appropriate to follow the suggested improvements. 
The current certification scheme, regulated by the EPBD directive 2018/844 [5], which amended the Directive 2010/31/EU, has not modified the articles related to issuing and displaying of the energy performance certificate (Articles 11, 12 and 13). Basically, the Directive requires the Member States to lay down the necessary measures to establish a system of certification of the energy performance of buildings, including a methodology for the calculation of the energy performance of buildings which shall be transparent and open to innovation. It also requires that the certificates are carried out by qualified and/or accredited experts. The certificate must include a list of recommendations for the cost-optimal or cost-effective improvement of the energy performance of a building or building unit. This list of recommendations can by standardized or tailor-made.

The EPC, according to the European Commission [6] should, in first place inform the owners and potential buyer/tenant about the energy performance of the building, and secondly inform the owners about profitable measures that can help improve the energy efficiency of the building. The rating and the RLMs are the most popular information requested on the EPC [7]. Even more, with the EPC content, several retrofitting tasks can be associated as a basis for the development of a retrofitting such as justification for refurbishment works, estimation of the budget costs and to demonstrate compliance with regulation targets [8].

Given that, in the certification scheme, the calculation of the energy performance is entrusted to a software along with others features such as the rating, energy savings and profitability. It becomes important to know whether these tools can be used effectively as multipurpose; for rating and for the estimation of energy savings in existing buildings, since these represent a more challenging task.

The aim of this study is to test if energy-labeling tools are able to deliver trustful information for renovation purposes, despite of being restricted to standardized values. The indicators used for this study are the energy consumption, energy saving variations and profitability. Additionally, the time spend by each method has been measured, for the standardized (labeling) and detailed (audit) procedure. Considering this data in combination with the previous results, suggestions are defined to improve the current certification process.

\section{Background}

Energy labeling tends to be similar in terms of purposes, but they vary significantly due to their local climate, needs and expectations [9]. This applies as well to the recommendation list and its elaboration, where two methods can be followed, standard or tailor-made list [10]. The standard list is obtained automatically when the data is uploaded to the certification system. The certifier might add more details, such as cost or additional suggestions. Since the tailor-made procedure has not been defined by the EPBD [10], this study will consider the procedure and results of the energy audit as a scheme to obtain savings and renovation measures under a tailor-made approach (Figure 1).

\subsection{Labeling}

Building energy certification and rating systems provide a standardized way to evaluate and compare energy use, energy efficiency, and energy costs in buildings. The primary purpose of such systems is to give owners, tenants, and other market stakeholders a convenient, non-technical way to distinguish among efficient and inefficient buildings, and to quantify the value of these differences [11].

Energy labeling tools used in EPC for residential buildings present several advantages in contrast with energy audits. Through their standardized procedure they simplify calculation, and their internal checking mechanisms are able to reduce the errors produced through energy efficiency practices [12,13]. They can also provide accurate energy savings on a statistical approach (energy saving program), across a large population of buildings. It is easy to adjust, and with the use of a comprehensive software system it may provide recommendations for upgrading the building to improve energy efficiency [14]. Labeling is much more affordable, since the cost of an energy audit in the residential sector may be 3 to 4 times as high as what the building owners are willing to pay [15]. 


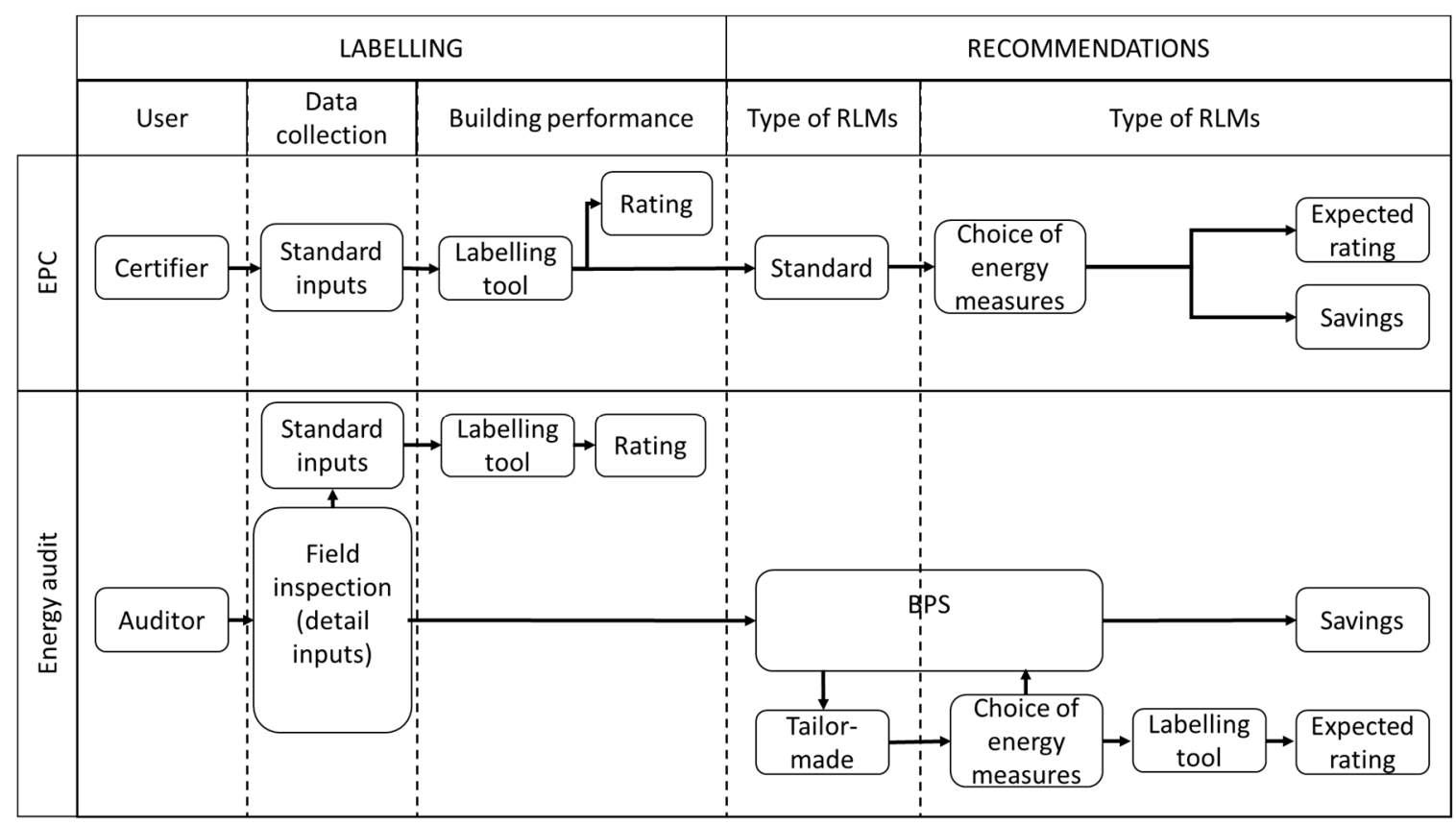

Figure 1. Flowchart of the Rating and Recommendation List of Measures (RLMs) based on the Energy Performance Certificates (EPC) and energy audit procedure.

Energy labeling in existing residential buildings represents a challenge in terms of the energy performance assessment of the building characteristics and system. This is because many information available for existing building is not updated or it remains unknown such as construction materials, level of insulation, drawings, retrofitting state, etc. Simplified methods for energy labeling are available in some countries where information for some of these parameters is included in the system based on statistic data, typically the U-values of the envelope, airtightness, and construction year. In Norway, input data is entered into an internet registration tool by the homeowner or by a certifier. The online tool has integrated validation rules to avoid the most inaccurate or incomplete input data. The minimal data required is building type, construction year, area of use and heating source. Based on this, and other information supplied by the user, an EPC with expected delivered energy is provided together with a list of recommendations where the user can select the most suitable ones.

A second type of procedure is the use of dedicated software for certification, which follows the national legislation or standard. In Norway, the use of exclusive software is not required, however a Norwegian commercial tool has included the energy labeling input data and calculation rules, and therefore is the most used tool by consultants and certifiers. This type of labeling software follows the most common calculation procedure adopted by many countries, since their use represent less time and resource consumption [16].

When the EPC is used in new buildings, it can be applied as a compliance tool for the building energy regulation and for the energy-labeling scheme. However, the same calculation procedure is used for existing buildings, where standardized inputs are used, although they may not match the actual characteristics of the building. This tool, should not only inform about the energy performance of the building, but also include the energy savings that certain improvements would have and provide key investment information such as cost optimal renovations alternatives and its savings. Meaning that the results are expected to differ from the real energy consumption [17].

\section{Energy Audit}

The main difference between energy labeling and energy audit is that the labeling is focused on comparing buildings, while audit is focused on analyzing an individual building. An energy audit, 
as it is defined by the AUDIT SAVE Project [18], is a systematic procedure that obtains data of the energy consumption profile of a building, identifies factors that have an effect on energy consumption and identifies and scale cost effective energy savings opportunities. An energy audit should provide accurate and concrete energy efficiency recommendations to improve the energy performance of a specific building $[19,20]$. Despite that, different types of energy audit that can be used, a single-family house cannot be audited by using a standardized model, due to different level of guidance that the housing stock requires [15].

An energy audit is not mandatory for EPC for residential buildings, but for a homeowner that is considering to renovate their home, an energy audit is recommended and it could be added as a next step of the EPC [17]. As it was mentioned previously an energy audit is a systematic procedure, where several tasks must be executed to gather adequate knowledge of the existing energy consumption profile of a building, such as energy bills analysis, field inspection, thermal envelope verification, airtightness value and examinations of the mechanical systems including ducts. With this data the auditor can run calculations through specialized software to estimate energy savings and to suggest concrete measures based on costs, benefits, and simple payback periods [21,22].

\subsection{Calculation Methods}

According to the EPBD requirement, the energy performance of buildings should be calculated based on a methodology that includes key factors that are relevant for the accuracy of the results. The energy performance should cover the annual energy demand of a building and it should consider EU standards. This raised the development of the ISO 13790:2008 by the European Committee for Standardization (CEN) and the International Organization for Standardization (ISO). The use of a normative calculation approach has several advantages, such as easiness, transparency, robustness and reproducibility, providing the best way to encourage energy performance rating [23]. As is stated by Lee, Fei and Augenbroe [24], the use of standardized approach is sustained on two main pillars. The first one is related to eliminating the modeler's bias by norming the assumptions. The second pillar refers to the definition of a unique scenario, which leaves aside the prediction of the actual uses of the building. Through its simplicity and unified modeling assumption this approach forms the basis for assessing building energy performance in a standardized and transparent way [13,25], being this independent of actual conditions of occupancy, behavior or weather [26].

Since the calculation is based on standardizations and the use of simplifications, inaccuracies are expected, compared to assessing the energy consumption in function of climatic zone, construction typology and user's profile. However these calculations are appropriate for energy characterization and energy labeling in buildings [27]. Despite the consensus about the uses of standardized procedure for labeling, the ISO 13790 presents several methods, each of them with different levels of robustness and simplification. Some drawbacks are expected when considering retrofitting buildings, since the labeling includes expected savings, energy renovation projects that should match the performance through the renovations. Therefore some doubts have risen about the EPCs procedure, such as the correctness of the calculation or the accuracy of the results as well as the use of climatic zones $[6,28]$.

As mentioned above, the most common calculation method for energy labeling for most of the countries, is based on a simplified monthly model which follows the ISO 13790:2008 [29,30]. However, the implementation may be different in each country since the standard contains many possible choices [31]. One of the main alternatives presented by the ISO 13790:2008 is the selection between two simplified methods, a monthly quasi-steady state and a simplified hourly method. Additionally the standard provides information about the use of detailed simulation software to ensure compatibility with the simplified calculation methods, as well as, procedure, boundary conditions and input data [32].

\subsubsection{Quasi-Steady State Methods}

As previously mentioned, simplified methods are based on monthly or hourly calculations and simplified description of the building (in terms of geometry, zones, U-values, etc.). The dynamic effects 
are taken into account by introducing correlation factors [23]. The effect of thermal inertia in the case of intermittent heating or switch off is considered separately (ISO 2008). This kind of methods has been in use for quite a long time, and gives reasonably accurate results for annual heating energy demand [29]. One of the limitation of this method is its inability to represent the energy impact of some important features of common types of air conditioning systems [30].

\subsubsection{Simplified Hourly Methods}

It is considered to be a simple method since it must rely on simple input data, the same input as used for the monthly method. The model is based on an equivalent resistance-capacitance model. It considers hourly steps and the input data can be modified each hour using schedule tables [33].

\subsubsection{Dynamic Calculation Methods}

A simple approach is normally used for evaluating the heating energy use of a residential building. Dynamic methods, however, evaluate the energy balance of a building repeatedly over small time steps, usually hourly, considering outside climate variations, occupancy, gains and losses through the envelope and effects of the heat stored in and released from thermal mass in building materials.

\subsection{Previous Studies}

Several studies have performed comparisons between methods, showing different results, e.g., Van Dijk et al. (2005) concluded that simplified calculation methods are consistent for the EPBD requirements for warm, moderate and cold climates in Europe. While other studies $[29,34]$ agree that simplified models may be appropriate for residential buildings with minor or no summer cooling, when the studies focus on trend or compare construction alternatives.

On the other hand, some studies present different observations about the use of the simplified method, Kokogiannakis et al. (2008), indicate that the monthly method shows disparate results compared with other methods, and those differences influence the rating of the building. Jokisalo and Kurnitski [35] demonstrate that EN ISO 13790 gives as much as $46 \%$ higher or 56\% lower building energy demand compared with a dynamic simulation tool, depending of the building type and its thermal inertia. Special attention is recommended $[36,37]$ to local climate and its impact on certain factors described in ISO 13790, which can lead to inaccurate results in certain locations.

\section{Methodology}

The methodology was developed in four steps; the first two steps were part of the simulation process of the energy demand of the building and different renovations options. The last two steps compared the labeling and energy audit procedures and the corresponding tools used through the indicators of costs and time.

The first step is to calculate the heating energy demand of the dwelling by using three different tools, each of which uses one of the standard calculation methods provided by the ISO 13790, quasi-steady state method, simplified hourly method and dynamic calculation method. Each tool was used under the procedure that would be carried out by the user assigned to each tool, homeowner, certifier and energy auditor.

The Second step is the implementation of several renovation options, which were selected from the list of suggestions delivered by the previous certificate of the dwelling. The full list of recommendations is presented in Table 1. Eight renovation measures were found suitable for the study, given that many of the suggestions do not require a simulation or are related to the behavior of the occupants. Each scenario introduces one energy measure, which were simulated by each tool. It is predictable that the results are not going to be similar among the tools; the aim of this step is to have a quantification of the differences in the results to later measure the cost-benefits with other relevant aspects for a decision-making. 
Table 1. List of recommendation measures included in the EPC of the building case.

\begin{tabular}{|c|c|c|}
\hline NO. & Recommendation & Used in the Study \\
\hline 1 & Install sealing strips & Not selected \\
\hline 2 & Sealing of air leaks & Selected \\
\hline 3 & Insulate cold ceilings & Selected \\
\hline 4 & Insulate roof or ceiling & Selected \\
\hline 5 & Insulate the floor at the ground & Selected \\
\hline 6 & Insulate exposed floors & Selected \\
\hline 7 & Insulate the floor edges & Not selected \\
\hline 8 & Back insulation of outer wall & Selected \\
\hline 9 & Insulation of basement wall & Selected \\
\hline 10 & Insulate ceiling cover & Not selected \\
\hline 11 & Replacement of window & Selected \\
\hline 12 & Replacement of the front door & Not selected \\
\hline 13 & Thermography and density testing & Not selected \\
\hline 14 & Switch to spare shower & Not selected \\
\hline 15 & Insulate hot water pipes & Not selected \\
\hline 16 & Mount a respirator on the kitchen fan & Not selected \\
\hline 17 & Replace the fan of the bathroom with a new one with moisture control & Not selected \\
\hline 18 & Install ventilation systems with heaters to replace mechanical ventilation & Not selected \\
\hline 19 & Install a control system for the exhaust fans of the ventilation systems & Not selected \\
\hline 20 & Switch to low energy light bulbs & Not selected \\
\hline 21 & Temperature and time control for the panel heaters & Not selected \\
\hline 22 & Temperature and timing control for the electric heating floor or roofs & Not selected \\
\hline 23 & Install new wood stove or fireplace, insert alternatively pellet stove & Not selected \\
\hline 24 & Install heat pump & Selected \\
\hline 25 & Install solar heating system & Not selected \\
\hline
\end{tabular}

The Third step uses the simulation results of the improvements to perform a Life Cycle Cost Analysis (LCCA), considering the energy saving and the cost of the implementation of the renovation measures. The results of this task will be the main indicators to evaluate the agreement between the labeling procedure and the audit, results that reflect the performance of the calculation method.

The fourth task assessed the effort that requires each method by recording the time spent in each process, assuming all the tasks that are needed to obtain the energy savings from the recommendations. This includes task such as transportation to the building, data collection for the inputs, measurements made on site, model generation, simulation process, etc. The estimation was made through the monitoring of the time used in each task during this study, it is also considered that the user behind each tool is an experienced simulator (except in the simple method were no experience is required).

\section{Material and Tools}

\subsection{Web-Based Tool}

EnergimerkeKalkulator is a website tool used in the certification scheme based on a self-assessment method. For the evaluation of existing buildings there are two options, where the first allows the homeowner (non-expert) to generate their own certificate, this option requires little technical information about the building, such as age of the construction, floor area, and energy sources. 
Many aspects are standardized, such as the building shape, windows and doors area, floor to ceiling height, etc. The second option requires information that is more detailed, High-level knowledge is not needed, but this option is more time consuming than the first one, especially the description of the envelope, where customized U-values can be added. This system intends to encourage the owners to be more involved and to stimulate their interest in energy efficiency [38].

\subsection{Simple Hourly Simulation Tool}

The Norwegian dynamic simulation tool Simien, which is the most popular BPS in Norway, can be used both to verify compliance with the building code (TEK) and for energy labeling. SIMIEN is based on the methodology described in the Norwegian standard NS 3031 [39] where most of the standardized input data is integrated in the software. This, together with the material database, enables faster simulation. For this simulation, the Norwegian standard is followed, as a consultant would do to perform the energy labeling of a Norwegian dwelling.

\subsection{Detailed Hourly Simulation Tool}

Design builder (DB) is an interface for the dynamic thermal simulation engine Energy Plus (EP). The software complies with the EPBD requirements. DB is a user-friendly software, which makes a 3D model of the input data and facilitates the data registration. DB allows running very detailed simulations, where parameters such as energy supply and energy dispersion can be included [40]. In this case, a more detailed approach is assumed, such as an energy audit where standard values are avoided and realistic input data are adopted. The input needed for each of the simulation tools is presented on Table 2 and Appendix A.

Table 2. Input data requirements by the three different types of tools.

\begin{tabular}{|c|c|c|c|c|c|c|c|c|}
\hline $\begin{array}{c}\text { Simulation } \\
\text { Type }\end{array}$ & Zones & Geometry & U-Values & $\begin{array}{l}\text { Internal } \\
\text { Gains }\end{array}$ & Occupancy & $\begin{array}{c}\text { HVAC } \\
\text { Set-Points }\end{array}$ & Ventilation & Infiltration \\
\hline Web-based & $\begin{array}{l}\text { Single } \\
\text { zone }\end{array}$ & Normalized & $\begin{array}{l}\text { Building } \\
\text { regulation } \\
\text { code }\end{array}$ & $\begin{array}{l}\text { set by the } \\
\text { standard }\end{array}$ & $\begin{array}{l}\text { set by the } \\
\text { standard }\end{array}$ & $\begin{array}{l}\text { set by the } \\
\text { standard }\end{array}$ & $\begin{array}{l}\text { set by the } \\
\text { standard }\end{array}$ & $\begin{array}{l}\text { set by the } \\
\text { standard }\end{array}$ \\
\hline Simple & $\begin{array}{l}\text { Single } \\
\text { zone }\end{array}$ & $\begin{array}{c}\text { Each } \\
\text { component } \\
\text { is described } \\
\text { manually }\end{array}$ & $\begin{array}{l}\text { Building } \\
\text { regulation } \\
\text { code }\end{array}$ & $\begin{array}{l}\text { set by the } \\
\text { standard }\end{array}$ & $\begin{array}{l}\text { set by the } \\
\text { standard }\end{array}$ & $\begin{array}{l}\text { set by the } \\
\text { standard }\end{array}$ & $\begin{array}{l}\text { set by the } \\
\text { standard }\end{array}$ & $\begin{array}{l}\text { set by the } \\
\text { standard }\end{array}$ \\
\hline Detailed & $\begin{array}{l}\text { Multi } \\
\text { zone }\end{array}$ & 3D modeling & $\begin{array}{c}\text { Full } \\
\text { description }\end{array}$ & inspection & Inspection & Inspection & Inspection & $\begin{array}{l}\text { Blower } \\
\text { door test }\end{array}$ \\
\hline
\end{tabular}

\subsection{Building Case}

To establish the baseline for the energy demands a real dwelling was used. The building corresponds to a wooden terraced dwelling located in Oslo, which represents the second most popular residential building in Norway [41]. The building was built in 1987 and consists of three levels; a basement and two upper floors as presented in Figure 1. The basement is reinforced concrete while the upper floors are made of wood frame. Although the house was built in the late 80's, the levels of insulation are quite high, this is because the Nordic countries have one of the strictest regulations in the EU, especially Norway, where the levels of insulation in housing were put in practices in the 40s. The dwelling has not been retrofitted, it is assumed to have its original insulation (about $20 \mathrm{~cm}$ ) and thermopanel windows. A description of some key parameters of the building are presented in Table 2 . The floor plan of the building is presented in Figure 2, and the geometry of the dwelling used in DB is in Figure 3. 


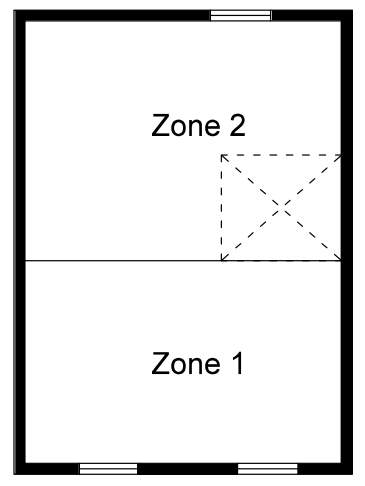

Basement

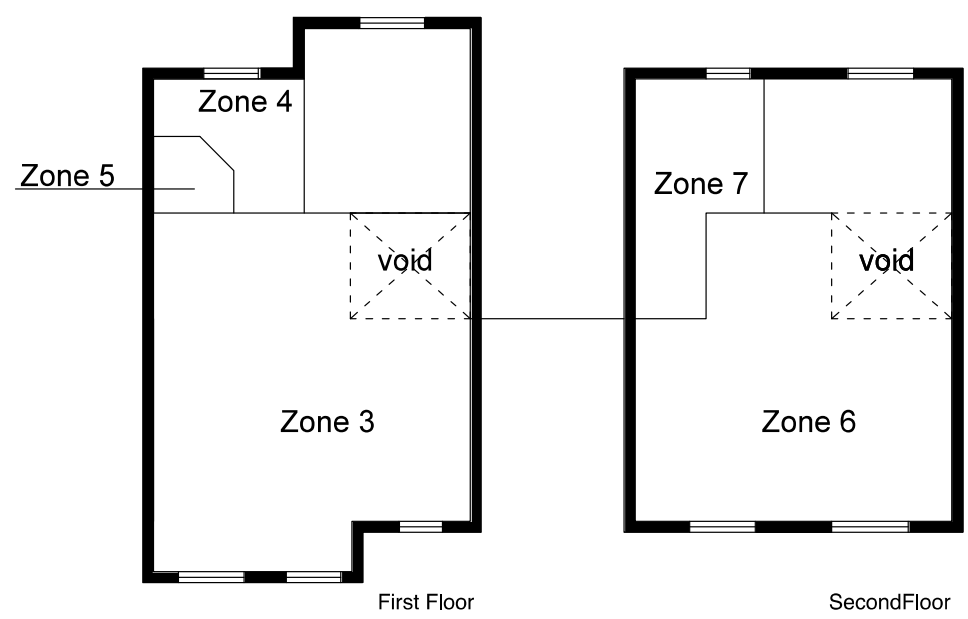

Figure 2. Floorplan of the building.

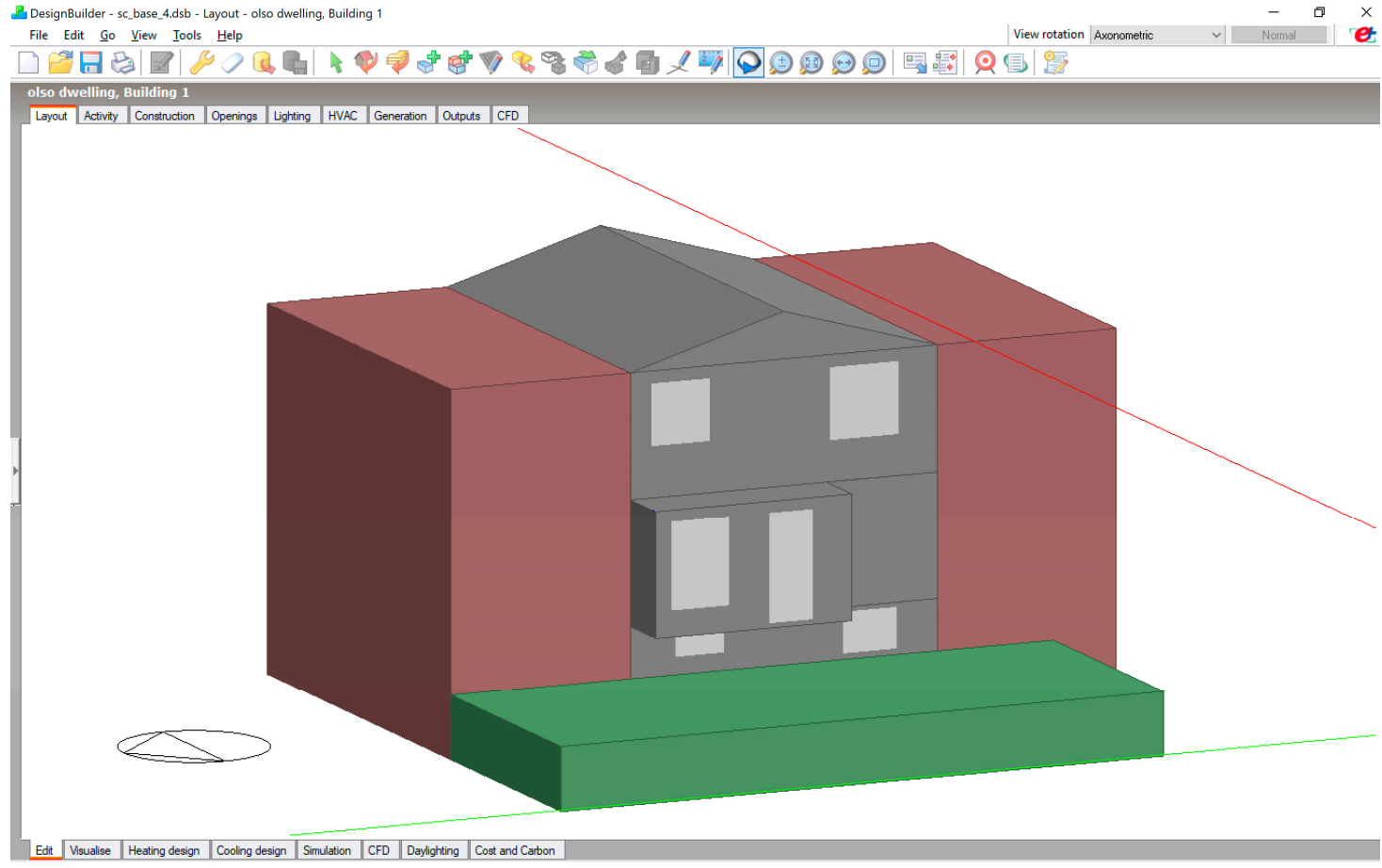

Figure 3. Dwelling representation in Design Builder.

\subsection{Life Cycle Cost}

The results from the different simulation tools and scenarios were used to determinate LCC for all the improvements, under the same economic assumptions. Total Tool (TT) were used for the calculation of the LCC assessment. The relevant measures identified and their prices (Norsk prisbok, 2017), can be seen in Table 3. 
Table 3. Description of the building and the improvements.

\begin{tabular}{ccccccc}
\hline \multirow{2}{*}{ NO. } & Saving Measures & \multirow{2}{*}{ Original } & \multirow{2}{*}{ Improved } & \multirow{2}{*}{ Quantity } & \multicolumn{2}{c}{ Initial Costs } \\
\cline { 5 - 7 } & & & & & NOK/Unit & KNOK \\
\hline 1 & U-value external walls & $0.28 \mathrm{~W} /\left(\mathrm{m}^{2} \mathrm{~K}\right)$ & $0.18 \mathrm{~W} /\left(\mathrm{m}^{2} \mathrm{~K}\right)$ & $54.1 \mathrm{~m}^{2}$ & 1193 & 10.4 \\
\hline 2 & U-value ceiling & $0.32 \mathrm{~W} /\left(\mathrm{m}^{2} \mathrm{~K}\right)$ & $0.13 \mathrm{~W} /\left(\mathrm{m}^{2} \mathrm{~K}\right)$ & $53.9 \mathrm{~m}^{2}$ & 65 & 3.2 \\
\hline 3 & U-value exposed floors & $0.2 \mathrm{~W} /\left(\mathrm{m}^{2} \mathrm{~K}\right)$ & $0.1 \mathrm{~W} /\left(\mathrm{m}^{2} \mathrm{~K}\right)$ & $6.14 \mathrm{~m}^{2}$ & 65 & 0.4 \\
\hline 4 & U-value ceiling basement & $0.3 \mathrm{~W} /\left(\mathrm{m}^{2} \mathrm{~K}\right)$ & $0.1 \mathrm{~W} /\left(\mathrm{m}^{2} \mathrm{~K}\right)$ & $46 \mathrm{~m}^{2}$ & 58.6 & 2.7 \\
\hline 5 & U-value windows $/$ doors & $1.9 \mathrm{~W} /\left(\mathrm{m}^{2} \mathrm{~K}\right)$ & $0.8 \mathrm{~W} /\left(\mathrm{m}^{2} \mathrm{~K}\right)$ & $19.8 \mathrm{~m}^{2}$ & 5077.8 & 100.5 \\
\hline 6 & Heat pump (air-air) & no & Yes & 1 & 25401.8 & 25.4 \\
\hline 7 & Ventilation type & Exahust & Balance & $100 \mathrm{~m}^{2}$ & 610 & 61.0 \\
\hline 8 & Air leakage at 50 Pa (N1 + N5) & $7.5 \mathrm{ACH}$ & $0.6 \mathrm{ACH}$ & - & $\mathrm{N} 1+\mathrm{N} 5$ & 111.0 \\
\hline
\end{tabular}

\section{Results}

\subsection{Simulation of Energy Demand and Energy Savings}

The results of the simulations made with the three tools, and eight improvement options are presented in Figure 4. There are great differences when it comes to the calculation of the heating demand between the three tools, being the simpler tool the one with higher heating energy demand (109 kWh $/ \mathrm{m}^{2}$ per year) followed by the simple method with $17 \%$ less energy. The largest differences are presented by the detailed method which estimates a $28 \%$ lower energy demand than the website tool. Therefore, three different base cases are defined. Although the differences between tools are expected, it is important to note that they have a key role in the aim of this study, since the base case will heavily influence the savings from each measure. In addition to the fact that the tools use different calculation methods, it was found that the differences are due to the detail of the input data. Standard-based data versus measurements have a great impact, even more than the calculation method itself, being the heating set point and the infiltration rates the inputs that disperse the most between standard-based data and measurements.

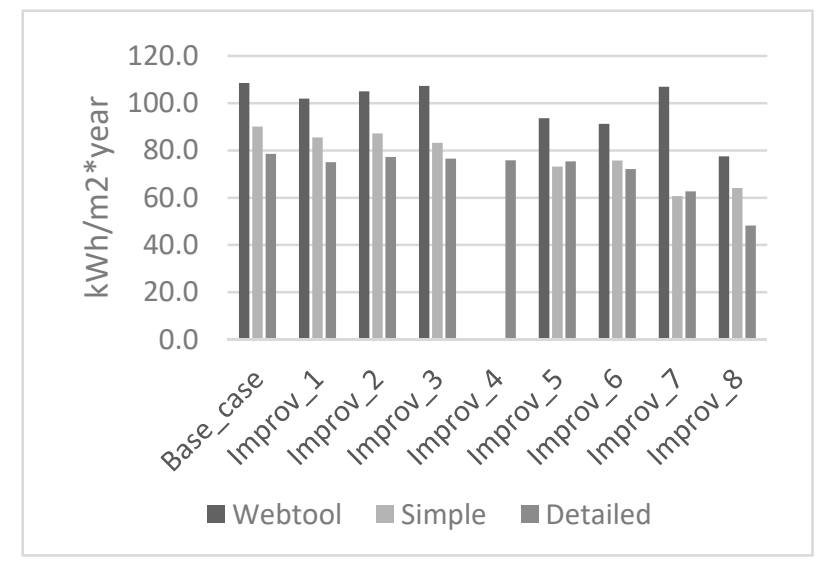

Figure 4. Heating energy demand.

When the energy measures where tested by each tool, the contrast of the results become more evident, since the biggest and lowest energy reductions by each tool are found in different improvements, see Figure 5. For instances the energy reduction obtained by improvement of the windows glassing with the standardized procedures, website tool and the simple method, reach $14 \%$ and $19 \%$ of reductions. Whereas the simulation used in the energy audit only score $4 \%$ of energy reduction. If all measures where applied, according to the energy audit method, a 75\% of energy reduction could be achieved. However, when applying the standardized procedure with the website 
tool, and the simple method, disparate results were obtained. The first tool delivers $50 \%$ of energy reduction while the simple method reaches $88 \%$. Improvements related to the heating systems also present great differences, this might be explained by the limited options to set the technical aspects of the improvements as well as the differences from the base case. The improvement No.4 (Table 3) is not presented in the simplified simulations since the standardized procedure is single zone simulation.

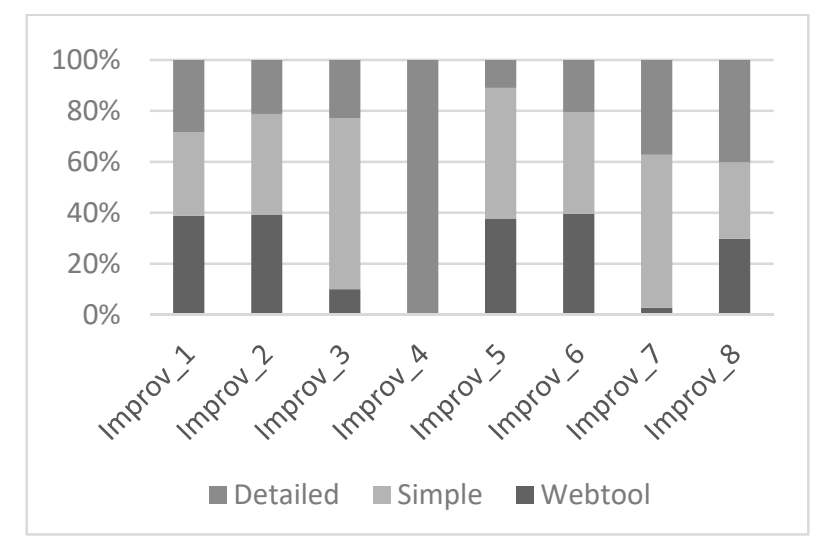

Figure 5. Percentage of energy reduction estimated by each tool and improvement.

\subsection{LCC of Improvements}

The life cycle cost gives important information about the impact of energy reductions and its convenience in economic terms. The results are presented in Table 4, which show the energy savings by each of the measures and the internal rate of return (IRR), set as $5 \%$ requirement. The results show that, whether the improvements turn out to be profitable or not, depends on the type of simulation used. The detailed simulation presents the lowest reduction values and with it, lower expectations of recovery of the investment. On the contrary, the results obtained with the website and the standardized simulation are much more optimistic, resulting in a higher number of profitable measures and a faster payback of the investment. This, combined with the different energy reductions gave overoptimistic results for some profitability measures, such us the improvement of the exposed floors, which represents a low investment, which makes it more sensitive and more likely to be profitable despite of the low amount of energy reduction in comparison with other measures.

Table 4. Life cycle cost (LCC) results for each scenario.

\begin{tabular}{ccccccc}
\hline \multirow{2}{*}{ NO. } & \multicolumn{3}{c}{ IRR (\%) } & \multicolumn{3}{c}{ Energy Saving (MWh/Year) } \\
\cline { 2 - 7 } & WT & ST & DT & WT & ST & DT \\
\hline 1 & 7.62 & 4.96 & 3.12 & 0.96 & 0.67 & 0.51 \\
2 & 14.30 & 11.96 & 16.36 & 0.50 & 0.42 & 0.06 \\
3 & 45.38 & 250.67 & 24.96 & 0.18 & 1.01 & 0.10 \\
4 & - & - & 13.32 & - & - & 0.40 \\
5 & -1.19 & -2.49 & -7.02 & 2.17 & 2.47 & 0.46 \\
6 & 3.84 & 1.40 & -7.63 & 2.52 & 2.10 & 0.95 \\
7 & -11.05 & 4.76 & 0.17 & 0.23 & 4.29 & 2.32 \\
8 & 2.02 & 1.05 & 1.89 & 4.52 & 3.80 & 4.42 \\
\hline
\end{tabular}

Figures 6-8 plot the cost versus energy demand for each of the eight renovation measures according to each calculation method. These show the disparity between the costs of benefits calculated with each procedure, where the optimum obtained does not match between them. 


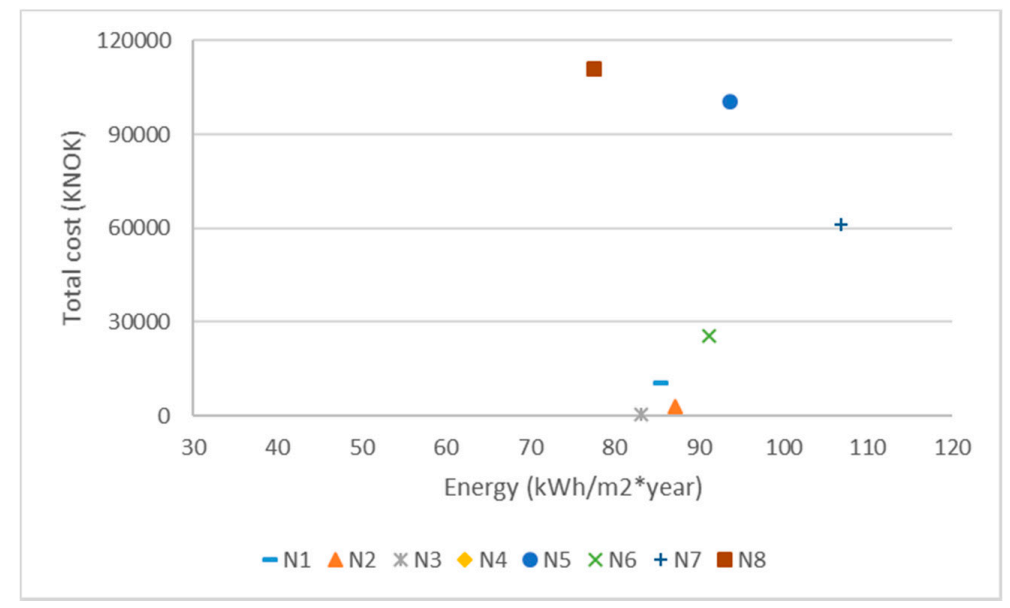

Figure 6. Distribution of each renovation measure calculated with the web-tool, regarding cost and energy demand.

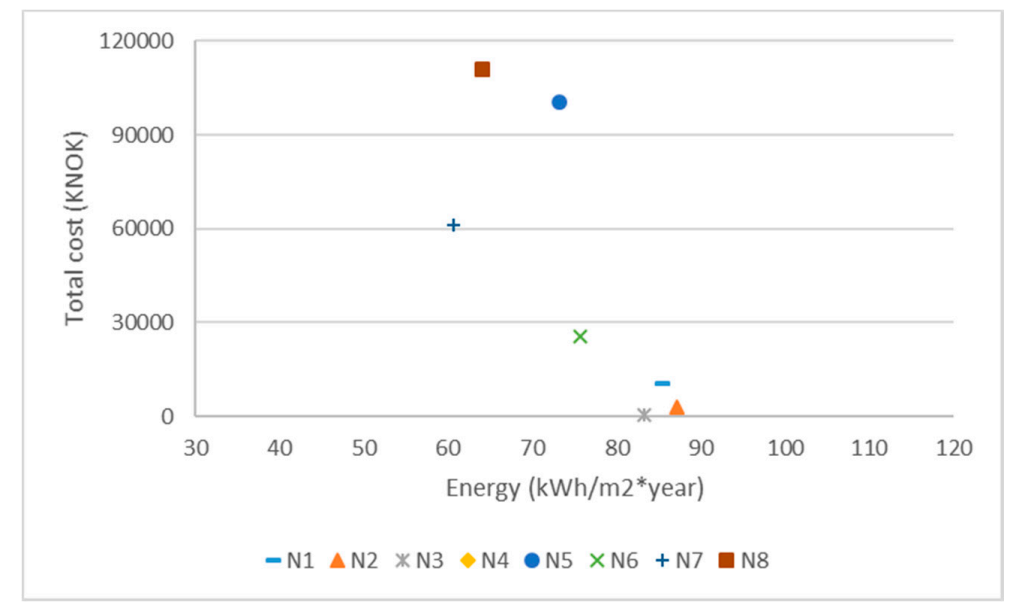

Figure 7. Distribution of each renovation measure calculated with the simple tool, regarding cost and energy demand.

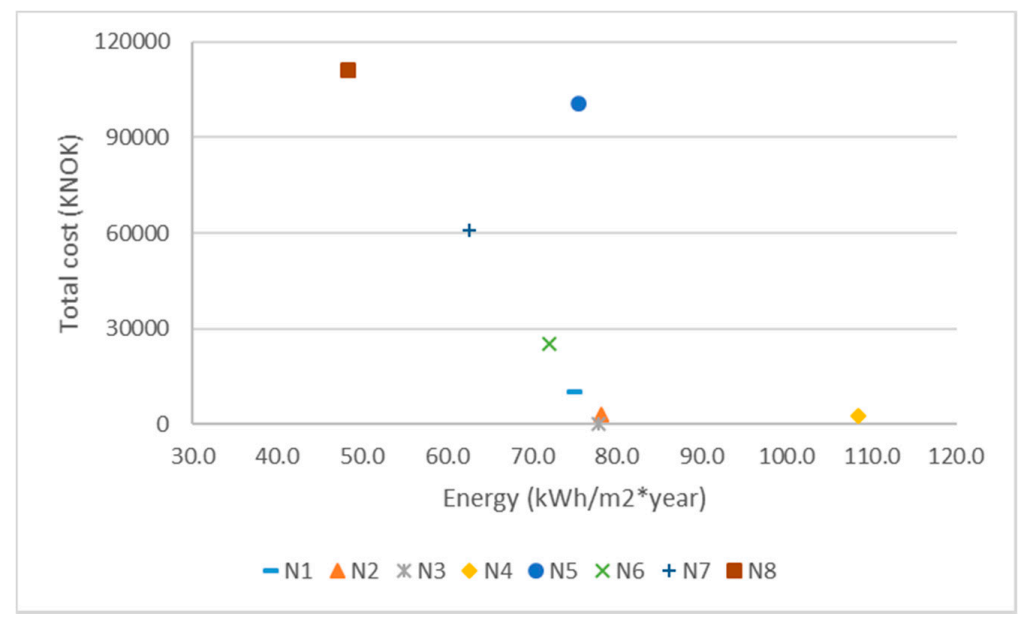

Figure 8. Distribution of each renovation measure calculated with the detailed tool, regarding cost and energy demand. 


\subsection{Time}

The time demanded by each tool to complete the simulation process was evaluated at each stage of the data collection, generation of the model, simulation and iteration to assess the improvements. The results can be seen in Table 5. Data collection is the task that impacts the most in the time invested in a simulation process, the quality (level of detail) and quantity of the required inputs by each tool is what makes the differences between a tool aiming at expert from a homeowner. Each tool requires different levels of expertise and the more detailed input requirements also require more time. For this task, it was considered the amount of work that needs to be done to collect the data, ranging from the transfer from the workplace to the location of the case study until the end of the inspection including the occupant's surveys. With this, the website tool is the one that needs less time to collect the information, summing up to one hour, since many steps are omitted. Followed by the simple method, with three hours. This procedure also adopts the official standard and with this, many assumptions are made, saving time. The audit requires up to $6 \mathrm{~h}$, since it requires many tasks to avoid assumptions for instance the measurement of the ventilation rate.

Table 5. Time demand for energy assessment.

\begin{tabular}{cccc}
\hline \multirow{2}{*}{ Tasks } & \multicolumn{3}{c}{ Hours } \\
\cline { 2 - 4 } & WT & ST & DT \\
\hline Transportation & - & 1 & 1 \\
Envelope & 1 & 1 & 1 \\
Interior zone & - & - & 1 \\
Surroundings & - & 1 & 1 \\
Property of the envelope & - & - & 1 \\
Property of the mechanical system & - & - & 0.3 \\
Ventilation rate measurements & - & - & 0.5 \\
Occupation-lighting-equipment & - & - & 1 \\
Modeling-inputs & 1 & 3 & 3 \\
Simulation & - & - & 0.2 \\
Iteration & 1 & 1 & 1 \\
\hline TOTAL & 3 & 7 & 11 \\
\hline
\end{tabular}

The time invested in the modeling of the building is a feature, strictly related to the software design. The website tool was created in a way that the homeowner can use it without spending that much time on it, a wizard interface assists the user through the whole process, giving predefined geometries to speed the task. The process followed by a certifier using Simmien, has the disadvantage of modeling the building by describing it by each orientation, introducing the wall area, and its windows, which makes the process slower. However, since it is a single zone simulation, some parts of the building are simplified, like the roof. This process took $3 \mathrm{~h}$ to be completed, keeping in mind that it was a small row house. For the detailed method, DB was used, which includes a $3 \mathrm{~d}$ modeling process. Because of this feature, it reduces the time for modeling and allowed to spend more time on introducing a large amount of inputs using the same time as the simplified method.

The testing of the retrofitting measures, was a clear drawback for the tools under standard process since none of them are designed to work with iterations, this is a tedious operation, where each wall and window properties must be re-defined one by one. With DB, this operation can be automated. However, the time that takes to run the simulation is longer than the time spent in the other tools, which takes a few seconds while in DB is about $10 \mathrm{~min}$. 


\section{Discussion}

EPCs and their underlying data is the main source of information on energy performance of existing buildings as it is stated in the evaluation and the proposal for the amending of the EPBD. However, the discussion about the list of recommendations is quite limited. Prove of this is the reduced amount of information about their practical uses for the retrofitting of existing buildings. This study rather than have an overview of the recommendations list usability as a hole, it is focused on the impact of standardized data and simplification on the LCC, which is the main factor in the renovation process taking the greatest share of the decision making. Through the comparison of the three tools to determinate the energy savings and their corresponding LCC analysis, two key aspects stand out.

Labeling and audit: The results from the labeling tools and the energy audit show important differences, which are expected since different inputs were used. This highlights an important shortcoming on the design of the recommendations list of measures as a tool for decision making, since it does not provide trustful information for renovation purposes. The authors agree that the main problem raises on the double use of the labeling input, to compare building and at the same time to provide cost-optimal renovations suggestions that should fit buildings individually. Key inputs can easily be obtained during the field visit or by the home owner, such as the number of occupants, the heating set points, ventilation rate, lighting gains etc. To incorporate this information should not be a great undertaking, and can be planned along with the labeling by just adding a double cell to certain inputs. By doing this the performance gap should be consistently reduced.

Cost-optimality: Since the requirement from the directive is to deliver recommendations that are cost-optimal, their performance in terms of cost and return of the investment should be clear. However, in its current form and on the lights of the results of this study this is not the case. Moreover, it is unclear if a certifier would perform a parametric analysis to evaluate the profitability of the different measures due to the lack of appropriate tools and the time needed to perform this analysis. One option could be to calculate RLMs through improvement measurements packages since many of the measures can be coupled and applied at the same time, avoiding losing opportunities for energy reductions. The profitability of the measures when they are coupled into the packages can help to make profitable improvements that are not profitable on their own, with this higher energy demand reductions can be obtained, as it is proposed in the Total Concept project [42].

It is also clear that delivering profitable recommendations, will require a one by one analysis, this is especially important in Norway since energy prices are quite low, and existing buildings have already high level of energy efficiency, which makes it more difficult to find profitable renovation measurements. One options to overpass this is to target existing buildings to net zero energy, an initiative that has been already been introduced in Norway through the passive house standard, NS 3701, but not yet connected to the labeling system. Multiple benefits beside energy reductions can be achieved by targeting net zero energy buildings, such as increased indoor environment quality, increased property value and reduction of the emission of greenhouse gases. Since in Norway what drives the renovation process on residential buildings is not the profitability but the tenant attractiveness, net zero energy buildings may help to trigger the renovation of the buildings stock.

\section{Conclusions}

A real dwelling was analyzed through the current labeling system required by the EPBD. The purpose of the analysis was to evaluate the usability of the RLMs included in the EPC to perform a renovation. To test the usability two requirements must be meet; first, they need to be accurate and secondly the must be profitable. To analysis this requirement three available means to obtain an EPC in Norway were tested, by a homeowner, certifier and by an energy auditor. For each of these procedures, the correspondent software were used; web tool, simple tool and detailed tool. Finally, the results were evaluated on a LCCA to test the profitability of the measures. 
Accuracy: From the simulation results from the different tools it is observable a discrepancy between the tools, not only the energy estimation, but in the order of relevance of the energy reductions of the measures. The simpler the tool and the procedure, the highest energy demand and savings were estimated. Therefore, the detailed procedure delivers a base case with precision but with low energy reduction expectations. Due to the differences between the calculation methods of the tools, more complex measures, such as the improvements of the heating and ventilation system, presented the highest dispersion among the methods.

Profitability: The energy calculated for the base case and the scenarios by each procedure did not yield similar or proportional results. Therefore, it is not unexpected that, something similar would happen with the profitability, with the simplest the procedure the greatest the payback of the measures while the detailed procedure gave a less rewarding result, in terms of the number of profitable measures and the IRR.

In view of the results obtained through the different methods and given the importance of the accuracy and profitability to follow a renovation project the authors agree that the certification tools in their current state are not capable of evaluating the RLMs included in the certificate, given the higher risk they present when using standardized data. Given that many of the recommendations in the list turned out to be unprofitable, it is considered that these should not be carried out without first making a detailed study.

To obtain more realistic energy savings, energy labeling should use both standards inputs and real occupations values for the RLMs calculation. However, these will rise the problem for a new tenant or owner of the property who will receive savings calculations for a set user-pattern that may not reflect his own, resulting on a different performance. One solution to this is to design a RLMs base on behavior scenarios where users can be encouraged to change their occupation practices to reduce energy use and obtain the most appropriated RLMs according to their target.

The energy audit presents the most robust procedure both in tasks and in the tools used. However, it also is the most expensive service. Despite this, the task can be easily reproduced by a certifier if the guidelines and tools are well designed to assist them. The extra time that requires is considerable, almost twice that the regular certification. However, the increase of fees should not be a serious barrier, since RLMs is one of the most requested features from the EPC and the only feature in the EPBD system that targets specifically existing buildings. The cost for an accurate EPC and RLMs should be seen as an investment rather than an extra cost.

Author Contributions: A.G.C. conceived and designed the research, did the state of the art research of the Norwegian building normative, LCC analysis and wrote the paper. M.D. participated in the simulation phase and in the writing of the paper.

Funding: This research received no external funding.

Conflicts of Interest: The authors declare no conflict of interest. 


\section{Appendix A}

Table A1. Inputs used during the Detailed Analysis with DB.

\begin{tabular}{|c|c|c|c|c|c|c|c|c|}
\hline Zone NO. & & 1 & 2 & 3 & 4 & 5 & 6 & 7 \\
\hline Floor & & Basement & Basement & 1 and 2 & 1st floor & 1st floor & 2nd floor & 2nd floor \\
\hline Room(s) & & Living room & $\begin{array}{l}\text { Corridor and } \\
\text { storage rooms }\end{array}$ & $\begin{array}{l}\text { Living room, kitchen, } \\
\text { corridor and storage room }\end{array}$ & Entrance & WC & Sleeping rooms & Bathroom \\
\hline \multirow{3}{*}{ Heating } & System & $\begin{array}{c}\text { Electric } \\
\text { radiators }\end{array}$ & No Heating & Electric radiators & No Heating & $\begin{array}{c}\text { Electric } \\
\text { radiators }\end{array}$ & No Heating & $\begin{array}{l}\text { Electric floor } \\
\text { heating }\end{array}$ \\
\hline & Set point $\left[{ }^{\circ} \mathrm{C}\right]$ & 19 & - & 22 & - & 22 & - & 24 \\
\hline & $\begin{array}{l}\text { Setback set } \\
\text { point }\left[{ }^{\circ} \mathrm{C}\right]\end{array}$ & 19 & - & 20 & - & 22 & - & 24 \\
\hline \multirow{5}{*}{ Ventilation } & System & $\begin{array}{c}\text { Natural, } \\
\text { single sided }\end{array}$ & $\begin{array}{c}\text { Natural, } \\
\text { single sided }\end{array}$ & Exhaust fan system & $\begin{array}{l}\text { Exhaust fan } \\
\text { system }\end{array}$ & $\begin{array}{l}\text { Exhaust fan } \\
\text { system }\end{array}$ & $\begin{array}{l}\text { Exhaust fan } \\
\text { system }\end{array}$ & $\begin{array}{c}\text { Exhaust fan } \\
\text { system }\end{array}$ \\
\hline & $\begin{array}{l}\text { Supply from } \\
\text { zone no. }\end{array}$ & Outdoors & Outdoors & Outdoors & zone 3 & zone 4 & Outdoors & zone 3 \\
\hline & $\begin{array}{l}\text { Exhaust to } \\
\text { zone no. }\end{array}$ & Outdoors & Outdoors & Outdoors & Outdoors & Outdoors & Outdoors & Outdoors \\
\hline & $\begin{array}{l}\text { Supply airflow } \\
\text { rate }\left[\mathrm{m}^{3} / \mathrm{h}\right]\end{array}$ & 30 & 10 & 90 & 36 & 36 & 104 & 54 \\
\hline & $\begin{array}{l}\text { Exhaust airflow } \\
\text { rate }\left[\mathrm{m}^{3} / \mathrm{h}\right]\end{array}$ & 30 & 10 & 108 & 36 & 36 & 104 & 54 \\
\hline \multirow{3}{*}{ Internal heat gains $[W]$} & People & - & - & 240 & - & - & 240 & - \\
\hline & Lighting & - & - & 120 & - & - & & - \\
\hline & Equipment & - & 50 & 100 & - & - & & - \\
\hline \multirow{3}{*}{$\begin{array}{l}\text { Schedules of parameters } \\
\text { which are not always on }\end{array}$} & $\begin{array}{l}\text { Space heating } \\
\text { night setback }\end{array}$ & - & - & mo-fr 23-17 sa-su 23-7 & - & - & & - \\
\hline & People & - & - & mo-fr 17-23 sa-su 7-23 & - & - & 23-July & - \\
\hline & Lighting & - & - & mo-fr 17-23 sa-su 7-23 & - & - & & - \\
\hline \multirow{3}{*}{$\begin{array}{l}\text { Surface material heat } \\
\text { capacity }\left[\mathrm{Wh} /\left(\mathrm{m}^{2} \mathrm{~K}\right)\right]\end{array}$} & Walls & 5 & 5 & 5 & 5 & 5 & 5 & 10 \\
\hline & Floor & 10 & 50 & 10 & 10 & 10 & 10 & 50 \\
\hline & Ceiling & 5 & 5 & 5 & 5 & 5 & 5 & 5 \\
\hline
\end{tabular}




\section{References}

1. Artola, I.; Rademaekers, K.; Williams, R.; Yearwood, J. Boosting Building Renovation: What Potential and Value for Europe? Study for the iTRE Committee, Commissioned by DG for Internal Policies Policy Department A; European Parliament: Brussels, Belgium, 2016; p. 72.

2. European Commission. Directive 2010/31/EU of the European Parliament and of the Council of 19 May 2010 on the energy performance of buildings (recast). Off. J. Eur. Union 2010, 153, 13-35.

3. Cappelletti, F.; Dalla Mora, T.; Peron, F.; Romagnoni, P.; Ruggeri, P. Building renovation: Which kind of guidelines could be proposed for policy makers and professional owners? Energy Procedia 2015, 78, $2366-2371$. [CrossRef]

4. Petersdorff, C.; Boermans, T.; Harnisch, J. Mitigation of $\mathrm{CO}_{2}$ emissions from the EU-15 building stock. beyond the EU directive on the energy performance of buildings (9 pp). Environ. Sci. Pollut. Res. 2006, 13, 350-358. [CrossRef]

5. European Commission. Directive 2018/844/EU of the European Parliament and of the Council of 30 May 2018 on the energy performance of buildings (amending Directive 2010/31/EU). Off. J. Eur. Union 2018, 156, 75-91.

6. European Commission. Commission Staff Working Document: Evaluation of Directive 2010/31/EU on the Energy Performance of Buildings. Accompanying the Document Proposal for a Directive of the European Parliament and of the Council Amending Directive 2010/31/EU on the Energy Performance of Buildings; European Union, European Commission: Brussels, Belgium, 2016; p. 109.

7. Petran, H.; Geissler, S.; Vlachos, S. D2.3-Report on Analysis of the Results-Survey at Retrofitting Companies, Energy Efficiency Programs Stakeholders and Final Users. ENERFUND, 2017; p. 133. Available online: http:/ / enerfund.eu/wp-content/uploads/2018/04/D2.3-Report-on-Questionnaires-andAnalysis_HP.v1.pdf (accessed on 15 June 2018).

8. Rotimi, A.; Bahadori-Jahromi, A.; Mylona, A.; Godfrey, P.; Cook, D. Estimation and Validation of Energy Consumption in UK Existing Hotel Building Using Dynamic Simulation Software. Sustainability 2017, 9, 1391. [CrossRef]

9. Hinge, A.; Neely, A.C.B.; Taylor, C. Building energy rating schemes around the world: What do we know. In Proceedings of the ACEEE, Pacific Grove, CA, USA, 17-22 August 2014.

10. Geissler, S.; Altmann, N. The role of recommendations in the Energy Performance Certificate. In How to Improve the Energy Efficiency of Existing Buildings. EPBD, 2015. Available online: https:/ / www.epbd-ca. eu/wp-content/uploads/2011/05/CA-EPBD-EPC-recommendations.pdf (accessed on 10 May 2018).

11. Institute for Market Transformation (IMT). A Roadmap for Creating Building Energy Rating Systems in Central Asia; Institute for Market Transformation: Washington, DC, USA, 2012; p. 8.

12. Hui, S.C.; Lee, R. Development of energy labels for residential buildings in Hong Kong. In Proceedings of the 10th Asia Pacific Conference on the Built Environment: Green Energy for Environment, Kaohsiung, Taiwan, 5-6 November 2009.

13. International Energy Agency (IEA). Energy Performance Certification of Buildings: A Policy Tool to Improve Energy Efficiency; IEA: Paris, France, 2010; p. 64.

14. Maldonado, E.; Wouters, P.; Panek, A. Supporting Transposition and Implementation of the Directive 2002/91/EC/CA-EPBD (2005-2007). EU CA EPBD Report. 2008. Available online: http:/ /www.buildup.eu/ sites/default/files/content/CA_Summary\%20report_Feb2010_0.pdf (accessed on 14 January 2018).

15. Väisänen, H.; Christensen, W.; Despretz, H.; Espegren, K.A.; Gaspar, C.; Lytras, K.; Meyer, B.; Reinikainen, E.; Sattler, M.; Starzer, O. Guidebook for Energy Audit Programme Developers. 2003. Available online: http:/ / www.energyagency.at (accessed on 31 June 2018).

16. Melo, A.P.; Cóstola, D.; Lamberts, R.; Hensen, J.L.M. Assessing the accuracy of a simplified building energy simulation model using BESTEST: The case study of Brazilian regulation. Energy Build. 2012, 45, 219-228. [CrossRef]

17. Concerted Action EPBD. Implementing the Energy Performance of Buildings Directive (EPBD)—Part A; ADENE: Lisbon, Portugal, 2016; p. 110.

18. MOTIVA. The Guidebook for Energy Audits Programme Schemes and Administrative Procedures-Final Report. 1999. Available online: https://www.motiva.fi/files/1804/Audit-final-report.pdf (accessed on 22 November 2017). 
19. Polly, B.; Kruis, N.; Roberts, D. Assessing and Improving the Accuracy of Energy Analysis for Residential Buildings; National Renewable Energy Lab. (NREL): Golden, CO, USA, 2011.

20. Hsu, D. How much information disclosure of building energy performance is necessary? Energy Policy 2014, 64, 263-272. [CrossRef]

21. Turner, W.C. Energy Management Handbook; Fairmont Press: Lilburn, GA, USA, 2001.

22. Khan, J. Evaluation of the Energy Audit Programme in Finland; AID-EE Report; Environmental and Energy Systems Studies, Lund University: Lund, Sweden, 2006.

23. Van Dijk, H.; Spiekman, M.; De Wilde, P. A monthly method for calculating energy performance in the context of European building regulations. In Proceedings of the Ninth International IBPSA Conference, Montreal, QC, Canada, 15-18 August 2005; pp. 255-262.

24. Lee, S.H.; Fei, Z.; Augenbroe, G. The use of normative energy calculation beyond building performance rating. In Proceedings of the 12th International Building Performance Simulation Association Conference, Sydney, Australia, 14-16 November 2011.

25. Hogeling, J.; Van Dijk, D. More Information on the Set of CEN Standards for the EPBD. 2008. Available online: http:/ / www.buildup.eu/sites/default/files/P060_EN_EPBD_CEN_March2008_p3031.pdf (accessed on 22 June 2018).

26. Pérez-Lombard, L.; Ortiz, J.; González, R.; Maestre, I. A review of benchmarking, rating and labelling concepts within the framework of building energy certification schemes. Energy Build. 2009, 41, 272-278. [CrossRef]

27. Bruno, R.; Pizzuti, G.; Arcuri, N. The prediction of thermal loads in building by means of the EN ISO 13790 dynamic model: A comparison with TRNSYS. Energy Procedia 2016, 101, 192-199. [CrossRef]

28. Moseley, P. Practical Approaches to the Building Renovation Challenge; European Commission EASME: Brussels, Belgium, 2016; p. 13.

29. ILETE. Labelling and Certification Guide-Part A-European Scenario; Agenzia Provinciale per l'Energia: La Provincia di Trento, Italy, 2010; p. 84. Available online: https:/ / ec.europa.eu/energy/intelligent/projects/ sites /ieeprojects / files / projects / documents/ilete_labelling_and_certification_guide_en.pdf (accessed on 15 December 2017).

30. Hitchin, R. Monthly air-conditioning energy demand calculations for building energy performance rating. Build. Serv. Eng. Res. Technol. 2016, 37, 298-315. [CrossRef]

31. CENSE. Leading the CEN Standards on Energy Performance of Buildings to Practice. Towards Effective Support of the EPBD Implementation and Acceleration in the EU Member States: Final Public Report. 2010, p. 61. Available online: https:/ / ec.europa.eu/energy/intelligent/projects/sites/iee-projects/files/projects/ documents/cense_taking_the_cen_epbd_standards_to_application_en.pdf (accessed on 11 December 2017).

32. Kokogiannakis, G.; Strachan, P.; Clarke, J. Comparison of the simplified methods of the ISO 13790 standard and detailed modelling programs in a regulatory context. J. Build. Perform. Simul. 2008, 1, 209-219. [CrossRef]

33. Millet, J.-R. The simple hourly method of prEN 13790: A dynamic method for the future. In Proceedings of the Clima 2007 WellBeing Indoors, Helsinki, Finland, 10-14 June 2007.

34. Al-Homoud, M.S. Computer-aided building energy analysis techniques. Build. Environ. 2001, 36, 421-433. [CrossRef]

35. Jokisalo, J.; Kurnitski, J. Performance of EN ISO 13790 utilisation factor heat demand calculation method in a cold climate. Energy Build. 2007, 39, 236-247. [CrossRef]

36. Michalak, P. The simple hourly method of EN ISO 13790 standard in Matlab/Simulink: A comparative study for the climatic conditions of Poland. Energy 2014, 75, 568-578. [CrossRef]

37. Kuster, C.; De carli, M.; Emmi, G.; Alesso, G. A Simplified Calculation Method to Evaluate Heating and Cooling Loads of Buildings. In Proceedings of the CLIMA 2016-12th REHVA World Congress 2016, Aalborg, Denmark, 22-25 May 2016.

38. Isachsen, O.; Rode, W.; Grini, G. Implementation of the EPBD in Norway Status November 2010. Country Reports on EPBD Implementation; Concerted Action EPBD. 2011. Available online: http:/ / www.buildup. eu/sites/default/files/Norway.pdf (accessed on 15 December 2017).

39. Justo Alonso, M.; Stene, J. State-of-the-Art Analysis of Nearly Zero Energy Buildings. Country Report IEA HPP Annex 40 Task 1-NORWAY; IEA HPP Annex 40; SINTEF Academic Press: Olso, Norway, 2013; p. 59. 
40. Rahman, M.; Rasul, M.; Khan, M.M.K. Energy conservation measures in an institutional building by dynamic simulation using DesignBuilder. In Proceedings of the 3rd IASME/WSEAS International Conference on Energy \& Environment, Cambridge, UK, 23-25 February 2008.

41. Thyholt, M.; Dystad Pettersen, T.; Haavik, T.; Wachenfeldt, B. Energy analysis of the Norwegian dwelling stock-IEA Task 37. IEA SHC, 2009; p. 66. Available online: https:/ / www.sintef.no/globalassets / project/ eksbo/dwelling_stock_analysis_norway_010409.pdf (accessed on 8 May 2018).

42. Wahlström, Å.; Maripuu, M.-L.; Abel, E. Total Concept_For Better Decisionmaking about Energy Efficiency Investments in Non-Residential Buildings; Energy Efficiency First: The Foundation of Low Carbon Society; ECEEE: Stockholm, Sweden, 2015.

(C) 2018 by the authors. Licensee MDPI, Basel, Switzerland. This article is an open access article distributed under the terms and conditions of the Creative Commons Attribution (CC BY) license (http:// creativecommons.org/licenses/by/4.0/). 